\title{
MALIGNANT HEMATOLOGIC FINDINGS BEYOND TYPICAL ENDOCRINE CONDITIONS
}

\author{
Assoc. Prof. Adina Ghemigian ${ }^{1,3}, \mathrm{MD}, \mathrm{PhD}$, Lecturer Ana Valea ${ }^{2,4}, \mathrm{MD}, \mathrm{PhD}$, \\ Nicoleta Dumitru ${ }^{3}$, MD, PhD student, Univ. Assist. Mara Carsote ${ }^{1,3}$, MD, PhD, \\ Univ. Assist. Eugenia Petrova ${ }^{1,3}$, MD, PhD, Andra Cocolos ${ }^{3}$, MD, PhD student \\ I "Carol Davila" University of Medicine and Pharmacy \\ 2"Iuliu Hatieganu” University of Medicine and Pharmacy \& \\ 3 "C.I. Parhon" National Institute of Endocrinology, Bucharest \\ ${ }^{4}$ Clinical County Hospital, Cluj-Napoca
}

\begin{abstract}
Endocrine morbidities are a vast panel of conditions; the most frequent diseases in daily endocrine practice are typically thyroid nodules or primary osteoporosis. We aim to introduce two cases who underlined a hematologic malignancy in association with apparently low risk endocrine conditions involving thyroid, respective osteoporosis field. A 24-year female is admitted for anterior cervical lumps which she self-detected one month ago. Normal thyroid blood assays are associated with neck ultrasound anomalies as: 2 thyroid nodules of $0.5 / 0.3 \mathrm{~cm}$, respective of $0.5 / 0.2 \mathrm{~cm} ; 5$ left cervical lumps (largest at supraclavicle level of 1.5/ 0.7/1.5 $\mathrm{cm}$ ); 4 right lateral cervical lymph nodes; multiple similar lesions were also revealed at others neck areas largest at submandible level of 1.3/0.9/1.2 cm (right), respective 1.1/0.9/2.4 cm (left). Evaluation at oto-rhino-laringology, infectious disease was unrevealing; diagnosis of stage IIA Hodgkin lymphoma was established starting from ganglion biopsy. This is 78-year female, admitted for evaluation of bone loss under densumab for the latest year after a decade history of bisphosphonates. Secondary causes of osteoporosis or hypovitaminosis $\mathrm{D}$ were ruled out; computed tomography detected a small adrenal incidentaloma, whole body bone scintigrame did not reveal metastasis while flow cytometry of peripheral lymphocytes identified B monoclonal lymphocytosis/chronic lymphatic leukaemia with B cell starting from a mild elevation of white blood cells in routine hemogram. Behind classical endocrine conditions as goitre or osteoporosis, severe diagnosis might be found in situations as associated cervical nodes involvement, respective non-response to specific anti-osteoporotic therapy if active case finding strategies in a multidisciplinary manner are performed.
\end{abstract}

Keywords: osteoporosis, lymphoma, thyroid

\author{
Abbreviations \\ $\mathbf{c m}=$ centimetre \\ 25OHD = 25-hydroxyvitamin D \\ BMD = Bone Mineral Density \\ DXA = Dual-Energy X-Ray Absorptiometry
}

\author{
GnRH = Gonadotrope Releasing Hormone \\ PET-CT = Positron Emission - Computed Tomography \\ $\mathbf{T S H}=$ Thyroid Stimulating Hormone
}

\section{INTRODUCTION}

Endocrine morbidities are a vast panel of conditions; the most frequent diseases in daily endocrine practice are typically thyroid nodules or dysfunction of the mentioned gland, as well as primary osteoporosis like menopause or age related type in older female population (1-3). One of the classic sequences of evaluation is the detection of enlarged cervical lymph nodes which leads to the indication of thyroid exploration, respective endocrine checkup as the next practical step of clinical approach (4-6). Lateral neck lumps involvement is related to infectious diseases, oncologic morbidities as general hematologic disorders as leukaemia or lymphoma, head and neck cancers, including those with primary site at thyroid region etc. (7-9). Another scenario is related to the panel of investigations for severe osteoporosis which is non-responsive to traditional anti-osteoporotic medication and 
a secondary cause including a malignancy may actually be involved (10-12).

\section{AIM}

We aim to introduce two cases from two different Romanian centres of endocrinology who underlined a hematologic malignancy in association with apparently low risk typical endocrine cases involving thyroid, respective osteoporosis field. Our comments are from an endocrinologist's perspective and case-finding strategy.

\section{MATERIAL AND METHODS}

This is a cases series report. The patients signed consent for anonymously use of their medical data. The thyroid and bone profile as evaluated during admission is introduced and discussed.

\section{RESULTS: CASES SERIES REPORT}

\section{Case 1}

This is a 24-year old non-smoker female patient who is referred for anterior cervical lumps which she self-detected one month ago. She also presents bradimenorrhea since last 6 months for whom she was assessed as an outpatient on a different gynaecological centre. At that moment, diagnosis of polycystic ovary syndrome was established and she was treated for 6 months with oral contraceptives (estro-progestives) without normalization of menses. She also has been evaluated by a specialist in oto-rhino-laringology and no particular condition was found. Further on, an endocrine check-up was considered. On admission, clinical exam showed anterior cervical adenopathies and irregular goitre on an underweighted patient (a body mass index of $18 \mathrm{~kg} / \mathrm{sqm}$ ). Biochemistry assays as well as blood hemogram were within normal limits. Normal thyroid function was identified based on TSH (Thyroid Stimulating Hormone) of $0.76 \mu \mathrm{UI} / \mathrm{ml}$ without thyroid autoimmunity (a thyroperoxidase antibody level of $10 \mathrm{UI} / \mathrm{ml}$ with normal values less than 35 $\mathrm{UI} / \mathrm{ml}$ ) and negative calcitonin. Thyroid ultrasound showed a right lobe of 1.4 by 1.1 by $4 \mathrm{~cm}$, a left lobe of 1.1 by 1.3 by 4 centimetre $(\mathrm{cm})$ with two small nodules of 0.5 by $0.3 \mathrm{~cm}$, respective of 0.5 by $0.2 \mathrm{~cm}$ (Fig. 1). Moreover, on the left side five lumps were detected, the largest was at supra- clavicle level of 1.5 by 0.7 by $1.5 \mathrm{~cm}$. On the right lateral cervical side, four lumps were found of 0.8 by 0.5 by $1.1 \mathrm{~cm}$ the largest one, suggestive for lymph
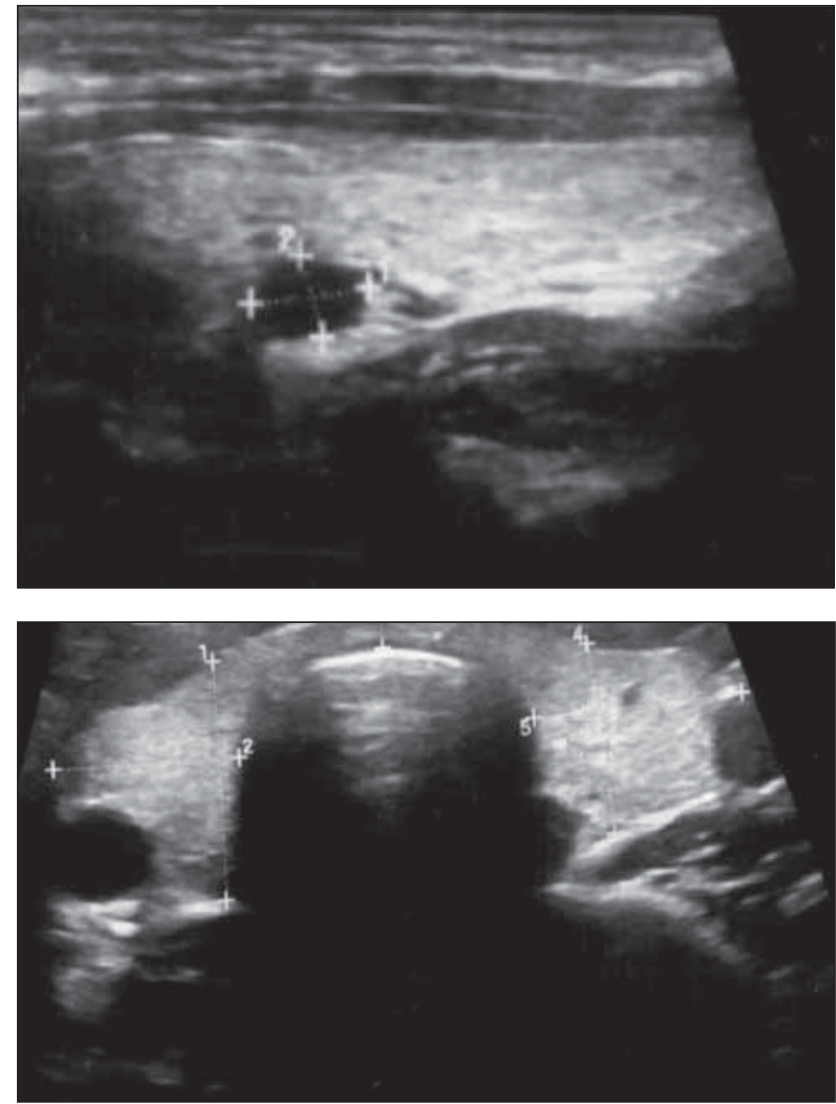

FIGURE 1. Thyroid ultrasound on a 23-year old female showing mild inhomogeneous pattern with small nodules without clinical significance

nodes enlargement. Multiple similar lesions were also revealed at others neck areas, the largest diameters at sub-mandible level were of 1.3 by 0.9 by $1.2 \mathrm{~cm}$ (right), respective 1.1 by 0.9 by $2.4 \mathrm{~cm}$ (left) (Fig. 2). She was referred to an infectionist and no particular disease was revealed and later on to haematology where ganglion biopsy was performed. The diagnostic of stage IIA Hodgkin lymphoma was established in addition to other imagery scans as PET-CT (Positron Emission - Computed Tomography) and chemotherapy was started. For ovarian protection, GnRH (Gonadotrope Releasing Hormone) analogue was initiated.

\section{Case 2}

This is 78-year old non-smoking female, with a history of kidney stones, hypercholesterolemia, arterial hypertension, and gastritis, admitted for evaluation of bone loss under adequate medication since last year. On admission, clinical exam reveals normal weight, normal blood pressure under adequate medication as well as normal thyroid gland examination. The family medical history is irrelevant. Her personal medical therapy includes surgical menopause at age of 46 years for a benign uterine condition, and, also, the diagnosis of osteo- 


\section{A. Right sub-mandible level: a lymph node of 1.3 by 0.9 by $1.2 \mathrm{~cm}$}

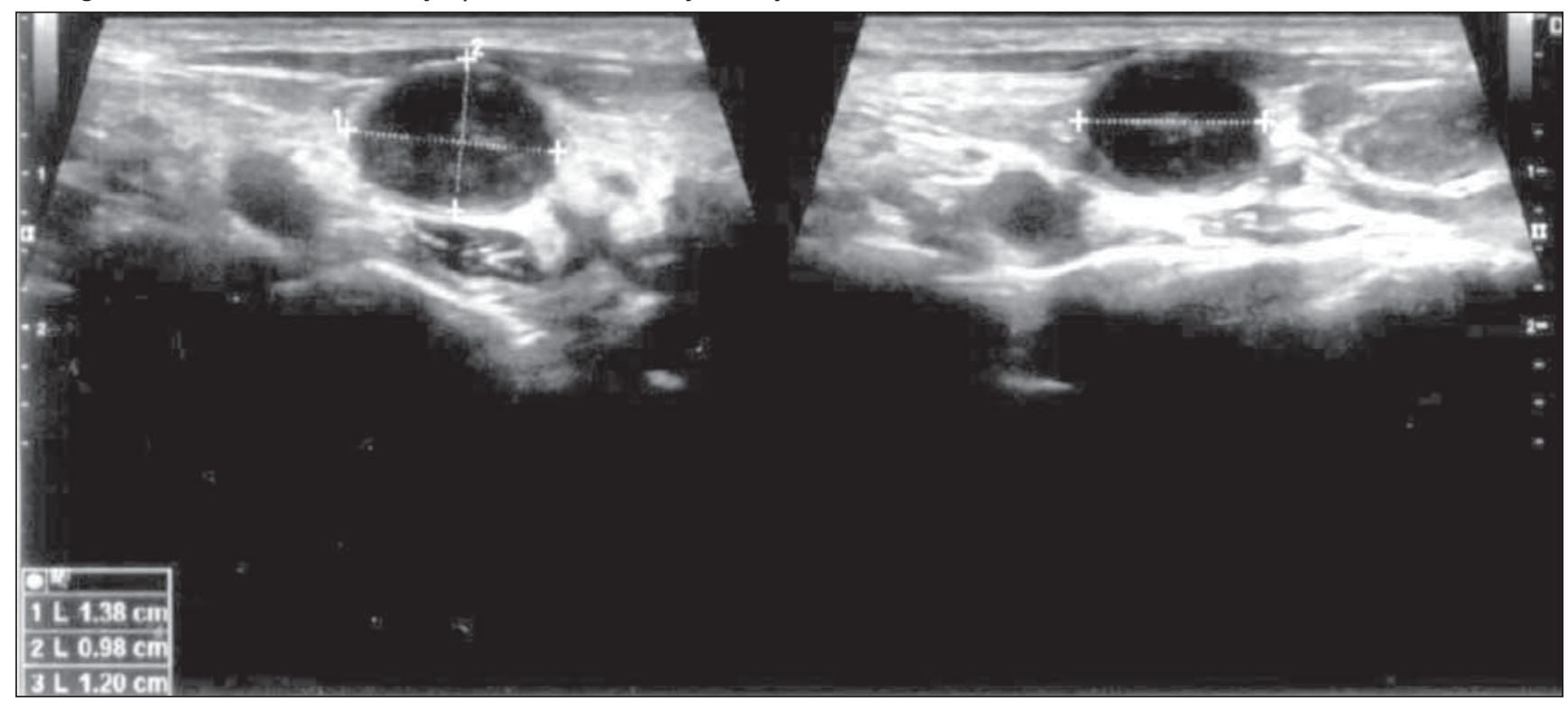

B. Right supraclavicle level: a lymph node of 0.8 by 0.5 by $1.2 \mathrm{~cm}$

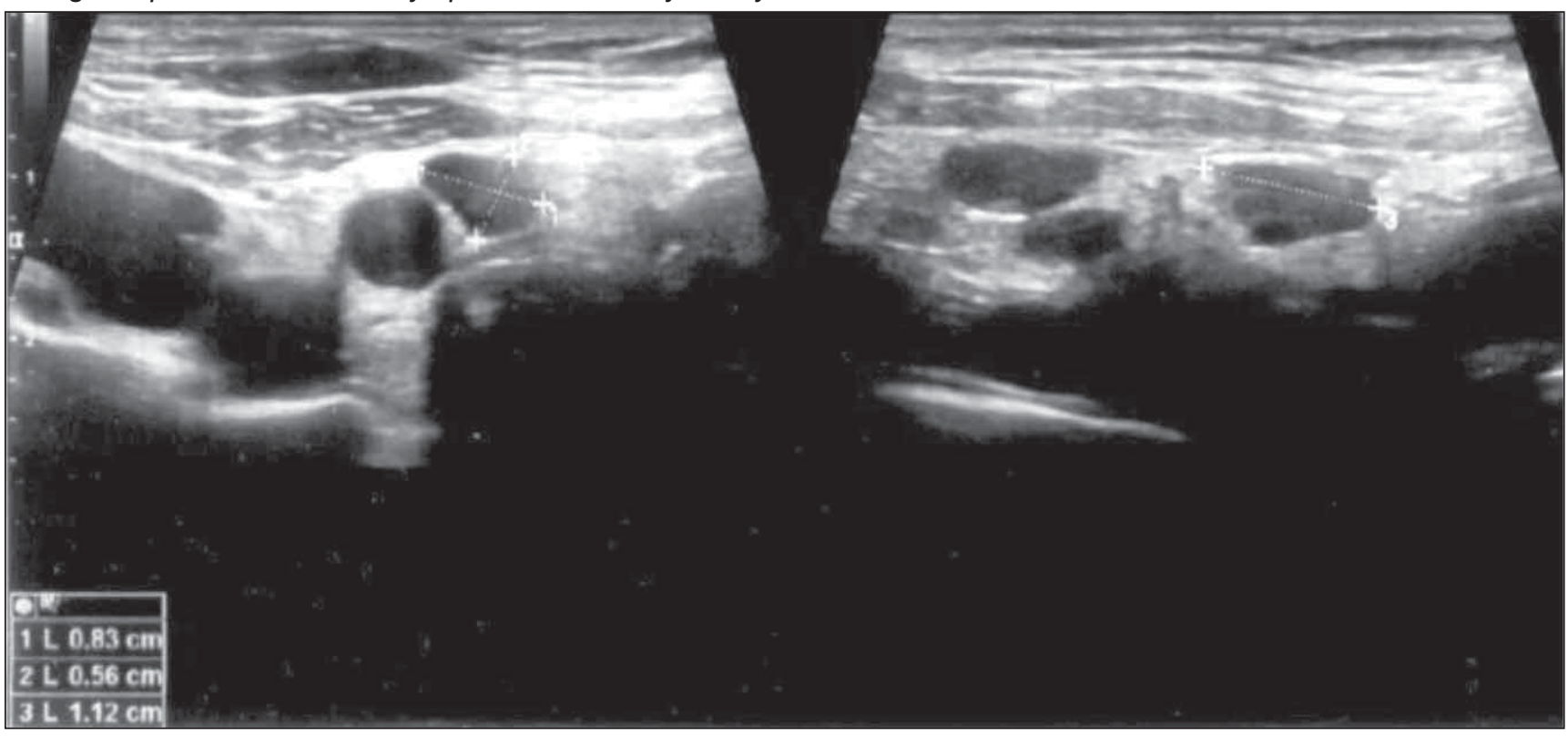

FIGURE 2. Neck ultrasound on a 23-year old female introducing multiple lymph nodes that were caused by a Hodgkin lymphoma type IIA

porosis several years ago, complicated with mild vertebral fractures which was treated for three years with weekly alendronate, for another three years with monthly oral ibandronate, then for three years with yearly zolendronic acid. During the last year, in addition to vitamin $\mathrm{D}$ supplements, denosumab was offered to the patient (subcutaneous $60 \mathrm{mg}$ at 6 months) with a Bone Mineral Density (BMD) decrease at central DXA (Dual-Energy X-Ray Absorptiometry) (Table 1, Fig. 3). Secondary cases of osteoporosis as persistent hypercorticism or primary hyperparathyroidism, hyperthyroidism were excluded; adequate levels of 25-hydroxyvitamin D were revealed in association with suppressed bone turnover markers as expected after prolonged ther- apy with anti-resorbtive medication (Table 2). The investigations also included profile X-ray of the thorax and lumbar vertebras pointing multiple thoracic vertebral fractures (Fig. 4). Whole body bone scintigrame ( $\left.{ }^{99 \mathrm{~m}} \mathrm{Tc}-\mathrm{HDP}, 20 \mathrm{mCi}\right)$ showed $\mathrm{T} 5$ thoracic vertebral fracture in course of consolidation and old VII-IX costal fractures at posterior right level (Fig. 5). Since no obvious cause of non-responsive osteoporosis, a computed tomography at thorax and abdominal level was performed but it proved non-diagnosis, except for a left adrenal incidentaloma of 1.1 by $1.8 \mathrm{~cm}$. A re-assessment of basic biochemistry parameters showed as seen initially a small increase of white blood cells number (of 12 5000, normal values between 4,000 and 
$10,000 / \mathrm{UL})$ with a higher than normal percent and number of lymphocytes (of 7.99, normal ranges between 0.6 and 3.4/UL, respective of $63.9 \%$, normal limits between 10 and $50 \%$ ) and decreased netrophiles percent $(30.5 \%$, normal between 37 and $80 \%$, count of 3,800 , normal between 2 and $6,900 /$ UL). Since this was the only unexplained anomaly at that moment, the patient was referred for a hematologic evaluation. Peripheral blood analysis of leucocytes distribution (flow cytometry of peripheral lymphocytes) showed $43 \%$ granulocytes, $5 \%$ CD4+ve/3-ve monocytes, 52\% lymphocytes (CD3+ve: 30\%; suppressor/helper ratio of 1.5), suggestive for the diagnosis of B line hyperplasia with clonal expansion of B monoclonal lymphocytosis/chronic lymphatic leukaemia with B cell. The patient was further followed-up by periodic hemogram and hematologic surveillance. Back to severe osteoporosis, from a limited number of medical options, zolendronic acid (intravenous $5 \mathrm{mg}$ per year) was re-introduced in association with vitamin D supplements. Further on, follow-up of DXA profile an adrenal mass is required.

TABLE 1. DXA results on a 78-year old female with almost a decade prior history of bisphosphonates who was treated with denosumab during last year (between 2016 and 2017) in association with vitamin D supplements

\begin{tabular}{|c|c|c|c|c|}
\hline \multirow{2}{*}{2016} & DXA region & $\begin{array}{c}\text { BMD } \\
\text { (g/sqcm) }\end{array}$ & $\begin{array}{c}\text { T-score } \\
\text { (SD) }\end{array}$ & $\begin{array}{c}\text { Z-score } \\
\text { (SD) }\end{array}$ \\
\cline { 2 - 5 } & L1-4 lumbar & 0.606 & -3.8 & -1.4 \\
\cline { 2 - 5 } & total hip & 0.688 & -2 & 0.1 \\
\hline \multirow{2}{*}{2017} & femoral neck & 0.610 & -2.1 & 0.1 \\
\cline { 2 - 5 } & L1-4 lumbar & 0.539 & -4.4 & -1.9 \\
\cline { 2 - 5 } & total hip & 0.730 & -1.6 & 0.3 \\
\cline { 2 - 5 } & femoral neck & 0.635 & -1.9 & 0.4 \\
\hline
\end{tabular}

$\mathrm{BMD}=$ Bone Mineral Density

TABLE 2. Calcium metabolism as reflected by blood assays on a 78-year old female with osteoporosis and long-time history of anti-resorptive medication

\begin{tabular}{|l|l|c|c|c|l|}
\hline \multirow{2}{*}{2017} & Parameter & Value & Normal & Units & $\begin{array}{l}\text { Obser- } \\
\text { vation }\end{array}$ \\
\hline & $\begin{array}{l}\text { Total/ionic } \\
\text { calcium }\end{array}$ & $9.4 / 3.8$ & $\begin{array}{c}8.4-10.3 / \\
3.9-4.9\end{array}$ & $\mathrm{mg} / \mathrm{dL}$ & \\
\cline { 2 - 5 } & phosphorus & 3.17 & $2.5-4.5$ & $\mathrm{mg} / \mathrm{dL}$ & \\
\cline { 2 - 5 } & $\begin{array}{l}\text { Alkaline } \\
\text { phosphatase }\end{array}$ & $\mathbf{1 9}$ & $38-105$ & $\mathrm{U} / \mathrm{L}$ & $\begin{array}{l}\text { Bone } \\
\text { formation } \\
\text { marker }\end{array}$ \\
\cline { 2 - 5 } osteocalcin & $\mathbf{8 . 2}$ & $15-46$ & $\mathrm{ng} / \mathrm{ml}$ & marker \\
\cline { 2 - 5 } & P1NP & $\mathbf{2 0 . 8}$ & $15-74$ & $\mathrm{ng} / \mathrm{ml}$ & \\
\cline { 2 - 4 } & CrossLaps & $\mathbf{0 . 2 3 5}$ & $0.33-0.782$ & $\mathrm{ng} / \mathrm{ml}$ & $\begin{array}{l}\text { Bone } \\
\text { resorption } \\
\text { marker }\end{array}$ \\
\hline & & 70 & $30-100$ & $\mathrm{ng} / \mathrm{ml}$ & \\
\hline & 25OHD & 60 & $15-65$ & $\mathrm{pg} / \mathrm{ml}$ & \\
\hline & parathormone & 60 & & & \\
\hline
\end{tabular}

$25 \mathrm{OHD}=25$-hydroxyvitamin $\mathrm{D}$

\section{A. Lumbar evaluation}

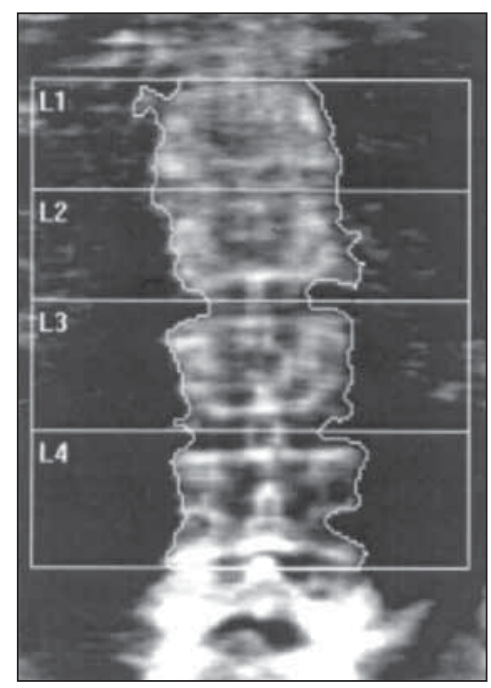

DXA Results Summary:

\begin{tabular}{|lccccccc|}
\hline Region & $\begin{array}{c}\text { Area } \\
\left.\mathbf{( c m}^{2}\right)\end{array}$ & $\begin{array}{c}\text { BMC } \\
\mathbf{( g )}\end{array}$ & $\begin{array}{c}\text { BMD } \\
\left(\mathbf{g} / \mathbf{c m}^{2}\right)\end{array}$ & $\begin{array}{c}\text { T- } \\
\text { score }\end{array}$ & $\begin{array}{c}\text { PR } \\
\mathbf{( \% )}\end{array}$ & $\begin{array}{c}\text { Z- } \\
\text { score }\end{array}$ & $\begin{array}{c}\text { AM } \\
\mathbf{( 5 )}\end{array}$ \\
1.1 & 13.82 & 6.42 & 0.465 & -4.2 & 50 & -1.9 & 69 \\
1.2 & 13.49 & 5.96 & 0.442 & -5.3 & 43 & -2.8 & 59 \\
1.3 & 15.08 & 7.51 & 0.498 & -5.3 & 46 & -2.7 & 63 \\
1.4 & 17.59 & 12.47 & 0.709 & -3.7 & 64 & -1.0 & 87 \\
Total & $\mathbf{5 9 . 9 8}$ & $\mathbf{3 2 . 3 5}$ & $\mathbf{0 . 5 3 8}$ & $-\mathbf{4 . 4}$ & $\mathbf{5 3}$ & $\mathbf{- 1 . 9}$ & $\mathbf{7 2}$ \\
\hline
\end{tabular}

Total BMD CV 1.0\%, ACT $=1.006, \mathrm{BCF}=0.989, \mathrm{TH}=7.034$ WHO Classification: Osteoporsis

Fracture Risk: High

$B$. Changes of DXA results after one year on denosumab (the most recent medication that was offered to the patient since last year)

L1-L4

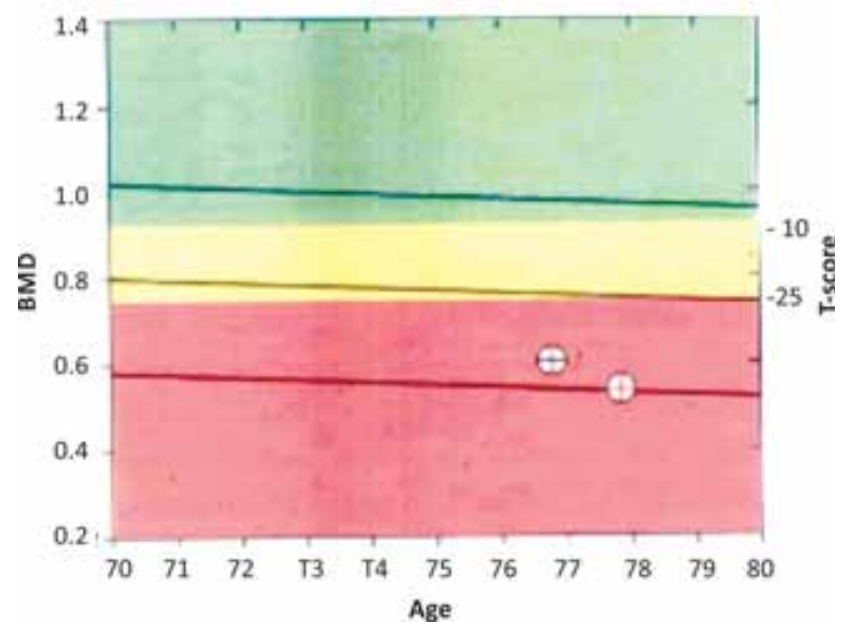

DXA Results Summary: L1-L4

\begin{tabular}{|l|c|c|c|c|c|}
\hline Scan Date & Age & $\begin{array}{c}\text { BMD } \\
\left(\mathbf{g} / \mathbf{c m}^{2}\right)\end{array}$ & $\begin{array}{c}\text { T - } \\
\text { score }\end{array}$ & \multicolumn{2}{|c|}{$\begin{array}{c}\text { BMD Change }\left(\mathrm{g} / \mathbf{c m}^{2} \text { ) }\right. \\
\text { vs Baseline }\end{array}$} \\
\hline 03.04 .2017 & 77 & 0.539 & -4.4 & $\begin{array}{c}-0.066 \\
(-11.0 \%)\end{array}$ & $\begin{array}{c}-0.066 \\
(-11.0 \%)\end{array}$ \\
\hline 14.03 .2016 & 76 & 0.606 & -3.8 & & \\
\hline
\end{tabular}

FIGURE 3. DXA assessment on a 78-year old female with a long medical history of treated osteporosis 


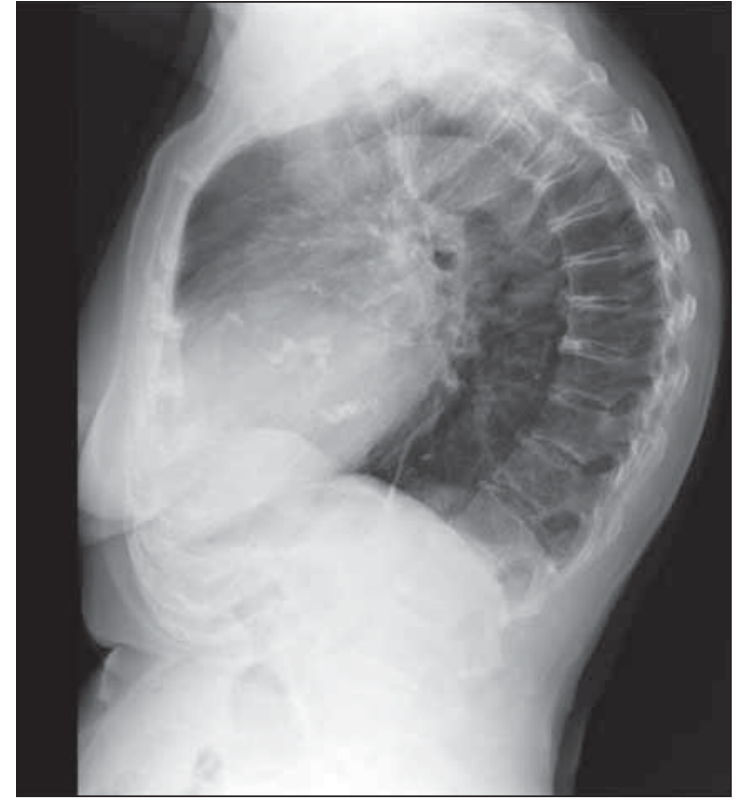

FIGURE 4. Profile X-Ray of the thorax vertebras pointing vertebral fractures in upper segment on a 78-year old female with primary osteoporosis

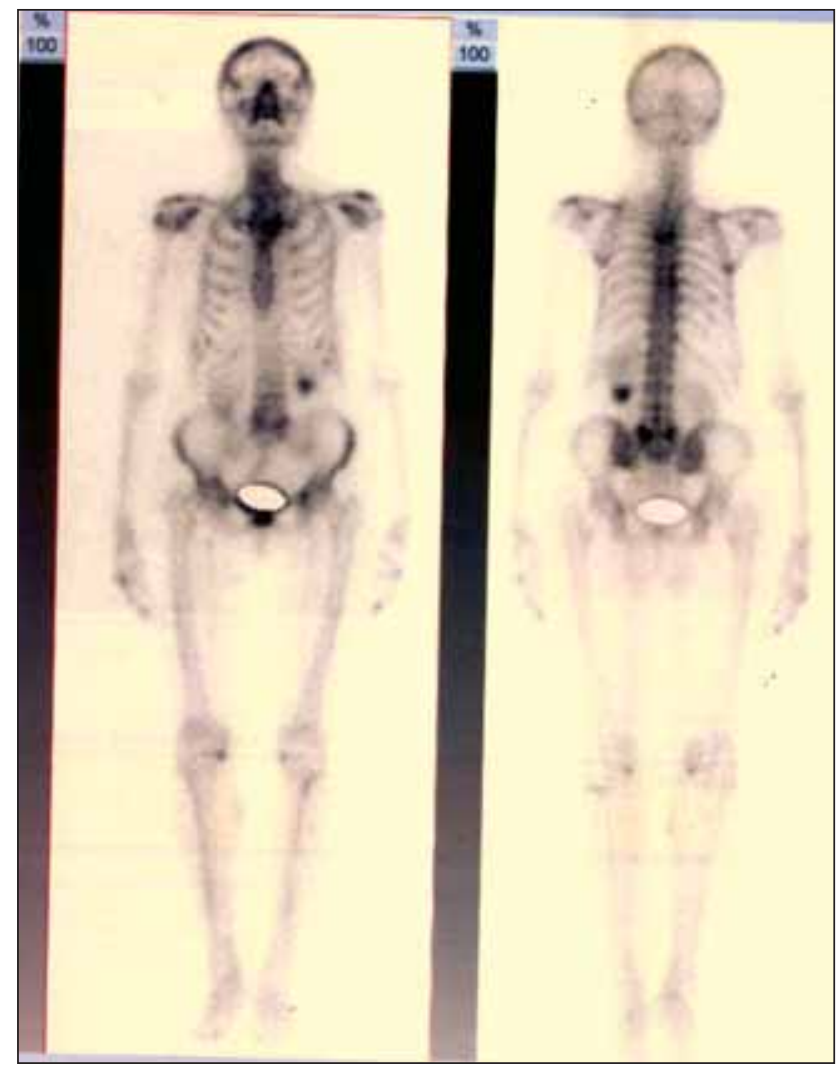

FIGURE 5. Whole body bone scintigrame ( ${ }^{99 m} T c-H D P$, $20 \mathrm{mCi}$ ) on a 78-year female shows T5 thoracic vertebral fracture in course of consolidation and old VII-IX costal fractures at posterior right level

\section{DISCUSSION}

These cases represent aspects of real-life medicine in daily endocrine practice where multi-disci- plinary team is essential for rapid diagnostic and starting adequate therapy in difficult cases. The first case introduces a young female with non-specific multi-nodular goitre which could not be related to multiple lymph nodes detected at neck area by self-palpation, clinical exam and routine ultrasound. A simple check-up, as was done in this case in the departments of oto-rhino-laringology and infectious diseases was not enough so ganglion biopsy was useful to obtain the identification of hematologic malignancy. Based on echography features a thyroid fine needle aspiration was not considered even the method is extremely useful for profiling the thyroid lumps (13). Even the patient had no other endocrine anomalies as those related to bones or pituitary gland field she also accused bradimenorrhea for the last 6 months which may be related with thyroid morbidities as autoimmune condition or thyroid dysfunction (14-16). This was not such a case and, retrospectively, we consider menses anomalies as potentially linked with hematologic malignancy.

The second case introduces a 78-year old female who, after a long history of specific anti-osteoporotic drugs, displays a significant bone loss. Secondary causes of osteoporosis were ruled out so the only logical anomaly that might explain it is the chronic hematologic disorder. The case finding strategy was rather difficult since computed tomography, whole body bone scintigram, and finally flow cytometry of peripheral blood were necessary. Nevertheless, a long-term severe osteoporosis is a risk factor itself for rather disappointing DXA results as seen in this case for the latest year under otherwise efficient medication for fracture risk reduction (17). The age, years since menopause, prior fragility fractures are also contributors to high risk profile of fractures, not necessarily the surgical menopause (18). However, despite BMD decrease, bone turnover markers were adequately suppressed at the end of anti-resorptive exposure (19-21). The patient was also diagnosed with a small non-functioning adrenal tumour; even the clear differential diagnosis with an adrenal metastasis may not be done at the moment, only based on serial imagery followed-up, we consider it an incidentaloma without a direct linked to bone status $(22,23)$. A final comment will be introduced related to potential options of therapy on a patient with malignancy and intolerance to oral bisphosphonates to whom injectable formulas of specific medication for osteoporosis are required, for instance, as used in this case, zolendronic acid $(24,25)$. 


\section{CONCLUSION}

Behind classical endocrine conditions as goitre or osteoporosis, severe diagnosis might be found in situations as cervical nodes involvement, respective non-response to specific anti-osteoporotic

\section{REFERENCES}

1. Haugen B.R., Alexander E.K., Bible K.C. et al. 2015 American Thyroid Association Management Guidelines for Adult Patients with Thyroid Nodules and Differentiated Thyroid Cancer: The American Thyroid Association Guidelines Task Force on Thyroid Nodules and Differentiated Thyroid Cancer. Thyroid. 2016; 26(1):1-133.

2. Lems W.F., Raterman H.G. Critical issues and current challenges in osteoporosis and fracture prevention. An overview of unmet needs. Ther Adv Musculoskelet Dis. 2017; 9(12):299-316.

3. Dumitru N., Ghemigian A., Carsote M. et al. Thyroid nodules after initial evaluation by primary health care practitioners: an ultrasound pictorial essay. Archives of the Balkan Medical Union. 2016; 51(3):434-438.

4. King S.K. Lateral neck lumps: A systematic approach for the general paediatrician. J Paediatr Child Health. 2017; 53(11):1091-1095.

5. Poiana C., Carsote M., Chirita C. et al. Thyroid nodules in patients with neuroendocrine tumors-two cases report, Timisoara Medical Journal, 2009; 59(4):371-374.

6. Tshering Vogel D.W., Thoeny H.C. Cross-sectional imaging in cancers of the head and neck: how we review and report. Cancer Imaging. 2016; 16(1):20.

7. Carsote M., Albu S.E., lorgulescu R. et al. From vasomotor symptoms to solid and insular papillary thyroid cancer with oxyphil variant areas. Journal of Surgical Sciences. 2015; 2(2):87-91.

8. Valea A., Radu O., Morar A. et al. Synchronous medullar thyroid cancer and primary hyperparathyroidism on a female within the sixth decade of life with positive family history for type 2A MEN syndrome. Journal of Medical Practice (Practica Medicala). 2016; 4(47)-11:346349.

9. Carsote M., Valea A., Dumitru N. et al. Metastases in daily endocrine practice. Archives of Balkan Medical Union. 2016; 51(4):476-480.

10. Gheorghisan-Galateanu A.A., Ghemigian A., Carsote M. et al. Cascade fractures despite improvement of DXA results and trabecular bone score assessment. Archives of Balkan Medical Union. 2016; 51(2):290-295

11. Albu S.E., Carsote M., Dumitrascu A. et al. The anabolic option in severe menopausal osteoporosis: is there a dark side? Archives of Balkan Medical Union. 2015; 50(2):292-295.

12. Poiana C., Paun D., Carsote M. et al. Există un fenotip al fracturii osteoporotice? Medicina Modernă 2012; XIX(3):121-124.

13. Gheorghisan-Galateanu A.A., Carsote M., Valea A. Incientaloma: from general practice to specific endocrine frame. J Pak Med Assoc. 2017; 67(6):917-922. therapy if active case finding strategies in multidisciplinary manner are performed.

\section{Acknowledgments}

We thank to our colleagues who helped us with these mentioned cases.
14. Valea A., Albu S.E., Petrescu R., Carsote M. Chronic thyroiditis and differentiated thyroid cancer: from overlapping high prevalence to a shift on multifocal intra-thyroid papillary thyroid carcinoma. Journal of Surgical Sciences. 2017; 4(1):38-45.

15. Ghemigian A., Carsote M., Dumitru N. et al. The bone profile after surgery for diferentiated thryoid carcinoma. Current Health Sciences Journal. 2016; 42(S5):39-42.

16. Valea A., Carsote M., Ghemigian A., Dumitrache C. Pituitary macroadenoma and thyroid autoimmunity: cross-sectional observations in adult population. Current Health Sciences Journal. 2016; 42(S5):50-53.

17. Diédhiou D., Cuny T., Sarr A. et al. Efficacy and safety of denosumab for the treatment of osteoporosis: A systematic review. Ann Endocrinol (Paris). 2015 Dec; 76(6):650-7.

18. Ghemigian A., Carsote M., Valea A. et al. Surgical menopause correlations with the bone status and the weight. Current Health Sciences Journal. 2015; 41(Suppl. 1):39-41.

19. Carsote M., Albu S.E., Ghemigian A., Valea A. Circulating serotonin and bone turnover markers are not correlated with a prevalent fragility fracture and menopausal osteopenia at central Dual-Energy X-Ray Absorptiometry. Archives of Balkan Medical Union. 2016; 51(2):284286.

20. Carsote M., Ghemigian A., Petrescu R. et al. Emerging approach of bone remodelling indices. Romanian Medical Journal (Revista Medicala Romana). 2016; LXIII(3):211-213.

21. Carsote M., Radu O., Dumitrascu A. et al. Bone and menopause: threshold of intervention. Romanian Medical Journal (Revista Medicala Romana). 2016; LXIII(3):233-236.

22. Gheorghisan-Galateanu A.A., Carsote M., Radoi V. et al. Menopausal osteoporosis in patients with bilateral adrenal tumors. Archives of Balkan Medical Union. 2016; 51(1):146-150.

23. Paun D., Radu O., Carsote M. et al. Bone indices on patients with adrenal tumors. Current Health Sciences Journal. 2016; 42(S5):35-38.

24. Dumitrache C., Paun D., Carsote M. et al. Therapy with zolendronic acid for menopausal osteoporosis: foccus on patients with breast cancer. Current Health Sciences Journal. 2016; 42(S5):28-30.

25. Carsote M., Ghemigian A., Radu O., Valea A. Teriparatide as option for severe osteoporosis. Journal of Medical Practice (Practica Medicală). 2016; 4(47)-11:324-330. 